\title{
Article \\ A Broadband Polarization-Insensitive Graphene Modulator Based on Dual Built-in Orthogonal Slots Plasmonic Waveguide
}

\author{
Wei Chen ${ }^{1}$, Yan $\mathrm{Xu}{ }^{1}$, Yang Gao ${ }^{1}$, Lanjing $\mathrm{Ji}^{2}$, Xibin Wang ${ }^{1}\left(\mathbb{D}\right.$, Xiaoqiang Sun $\left.{ }^{1, *} \mathbb{(}\right)$ and Daming Zhang ${ }^{1}(\mathbb{D}$ \\ 1 State Key Laboratory of Integrated Optoelectronics, College of Electronic Science \& Engineering, \\ Jilin University, Changchun 130012, China; chenwei18@mails.jlu.edu.cn (W.C.); \\ xyan17@mails.jlu.edu.cn (Y.X.); ygao17@mails.jlu.edu.cn (Y.G.); xibinwang@jlu.edu.cn (X.W.); \\ zhangdm@jlu.edu.cn (D.Z.) \\ 2 Institute of Marine Science and Technology, Shandong University, Qingdao 250100, China; \\ jilanting@sdu.edu.cn \\ * Correspondence: sunxq@jlu.edu.cn
}

Citation: Chen, W.; Xu, Y.; Gao, Y.; Ji, L.; Wang, X.; Sun, X.; Zhang, D. A Broadband Polarization-Insensitive Graphene Modulator Based on Dual Built-in Orthogonal Slots Plasmonic Waveguide. Appl. Sci. 2021, 11, 1897. https://doi.org/10.3390/app11041897

Academic Editor: Filippo Giannazzo Received: 10 February 2021

Accepted: 19 February 2021

Published: 21 February 2021

Publisher's Note: MDPI stays neutral with regard to jurisdictional claims in published maps and institutional affiliations.

Copyright: () 2021 by the authors. Licensee MDPI, Basel, Switzerland. This article is an open access article distributed under the terms and conditions of the Creative Commons Attribution (CC BY) license (https:// creativecommons.org/licenses/by/ $4.0 /)$

\begin{abstract}
A broadband polarization-insensitive graphene modulator has been proposed. The dual built-in orthogonal slots waveguide allows polarization independence for the transverse electric (TE) mode and the transverse magnetic (TM) mode. Due to the introduction of metal slots in both the vertical and horizontal directions, the optical field as well as the electro-absorption of graphene are enhanced by the plasmonic effect. The proposed electro-optic modulator shows a modulation depth of 0.474 and $0.462 \mathrm{~dB} / \mu \mathrm{m}$ for two supported modes, respectively. An ultra-low effective index difference of 0.001 can be achieved within the wavelength range from 1100 to $1900 \mathrm{~nm}$. The $3 \mathrm{~dB}$-bandwidth is estimated to be $101 \mathrm{GHz}$. The power consumption is $271 \mathrm{fJ} / \mathrm{bit}$ at a modulation length of $20 \mu \mathrm{m}$. The proposed modulator provides high speed broadband solutions in microwave photonic systems.
\end{abstract}

Keywords: graphene; plasmonic modulator; waveguide; polarization-insensitive

\section{Introduction}

High performance electro-optic (EO) modulators are highly demanded in wideband optics communication networks [1]. The lithium niobite-based modulators are mature but suffer from a large footprint [2]. Silicon modulators are compatible with CMOS technology, while facing the problem of low EO efficiency [3]. III-V based modulators offer a small footprint; however, the insertion loss and thermal stability are still to be improved [4]. $\mathrm{SiC}$-based waveguides also show application potential [5]. Due to the unsatisfactory EO properties of the above underlying materials, modulators that meet all requires are still elusive. Graphene with excellent EO characteristics has been well studied and widely adopted in optical modulators [6-9]. In 2011, Liu et al. experimentally presented a graphene modulator with a modulation depth (MD, the difference between "ON" state and "OFF" state) of $0.1 \mathrm{~dB} / \mu \mathrm{m}$ [10]. A built-in p-oxide-n-like junction graphene modulator exhibited an MD of $0.16 \mathrm{~dB} / \mu \mathrm{m}$ and a power consumption of $1 \mathrm{pJ} / \mathrm{bit}$ [11]. The graphene EO modulator with a high $3 \mathrm{~dB}-$ bandwidth of $30 \mathrm{GHz}$ has also been demonstrated [12]. However, the performance of above graphene modulators is limited by the weak interaction between the extremely thin graphene flake and the light field that is strongly bounded in the high index dielectric material. If the plasmonic effect is introduced, the light can propagate as a surface plasmon polarizations (SPPs) mode along the waveguide, which implies an enhanced optical field intensity. More optical power will be guided to the dielectric/graphene interface, facilitating the light-graphene interaction [13-15]. Huang et al. proposed a waveguide-coupled hybrid plasmonic graphene modulator with a $3 \mathrm{~dB}$-bandwidth of $0.48 \mathrm{THz}$ and an energy consumption of $145 \mathrm{fJ} /$ bit [16]. A hybrid plasmonic graphene modulator with a $3 \mathrm{~dB}$-bandwidth of $0.662 \mathrm{THz}$ and a power consumption of $118.7 \mathrm{fJ} / \mathrm{bit}$ 
promises good potential for hybrid plasmonic graphene EO modulators [17]. Another issue for the graphene modulator is the polarization sensitivity, which originates from the low absorption rate of $2.3 \%$ for the electric field polarization perpendicular to the graphene flake surface. Most reported works can only operate in transverse magnetic (TM) or transverse electric (TE) polarization independently [18]. The introduction of polarization control functions will inevitably complexify the device structure [19]. Therefore, a compact and polarization-insensitive graphene modulator with characteristic of broadband operation is desirable.

In this paper, we proposed a graphene modulator based on a dual built-in orthogonal slots waveguide (DBOSW). The geometric parameters of the hybrid plasmonic waveguide are investigated and optimized by finite element method (FEM). The mechanism of polarization insensitivity and broadband modulation is elaborated in detail. Our proposed waveguide structure overcomes the strict polarization dependence of plasmonic-based waveguides. Moreover, the DBOSW graphene modulator realizes broadband modulation with excellent polarization independence, which shows good potential in microwave photonic systems.

\section{Configuration and Structure}

\subsection{Device Structure}

As shown in Figure 1, the proposed graphene modulator based on the dual built-in orthogonal slots waveguide consists of a bottom silver layer $\left(\mathrm{Ag}, n_{\mathrm{Ag}}=0.14447+11.366\right)$, a middle silica layer $\left(\mathrm{SiO}_{2}, n_{\mathrm{SiO} 2}=1.45\right)$ and a top silver slot isolated by $\mathrm{SiO}_{2}$. Double $0.33 \mathrm{~nm}$-thick graphene flakes are isolated by $15 \mathrm{~nm}$-thick $\mathrm{SiO}_{2}$ and cover the hybrid waveguide. The metal stacks-graphene contacts form the electrodes [20]. The whole structure is supported by the $\mathrm{SiO}_{2}$ substrate.

(a)

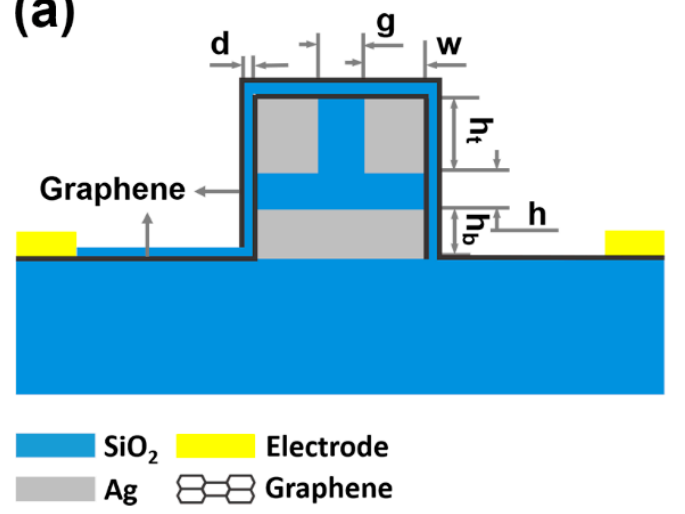

(b)

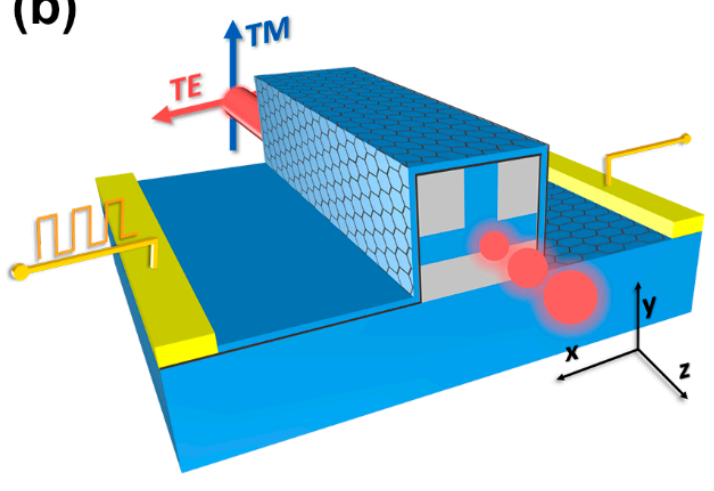

Figure 1. (a) Two-dimensional (2D) cross section; (b) three-dimensional (3D) view of the graphene modulator with dual built-in orthogonal slots waveguide.

Graphene plays a major role in optical modulation of this modulator. As shown in Figure 2a, the transmission spectrum of DBOSW with a modulation length of $L=20 \mu \mathrm{m}$ covered with graphene-SiO${ }_{2}$-graphene stacks but without applied voltage $\left(\mathrm{U}=0 \mathrm{~V}\left(\mu_{\mathrm{c}}=0 \mathrm{eV}\right)\right)$ has a sharp drop compared to DBOSW without graphene. This large significant light loss mainly originates from the light absorption effect of graphene, indicating that graphene has an effective light modulation function. 
(a)

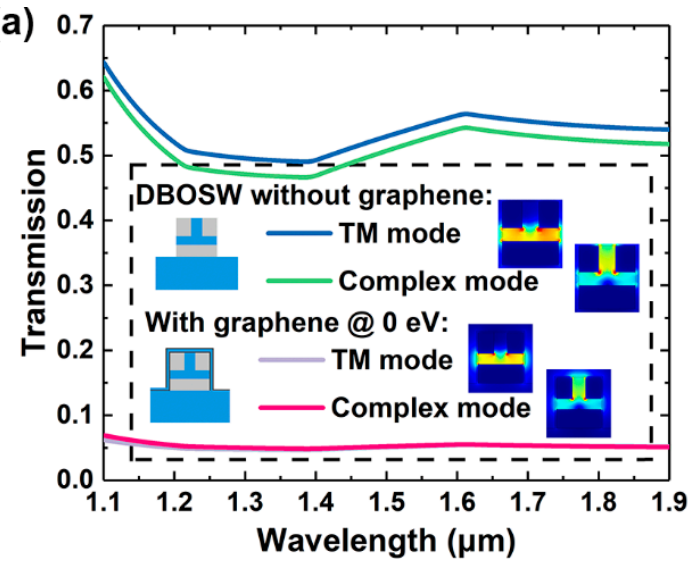

(b)

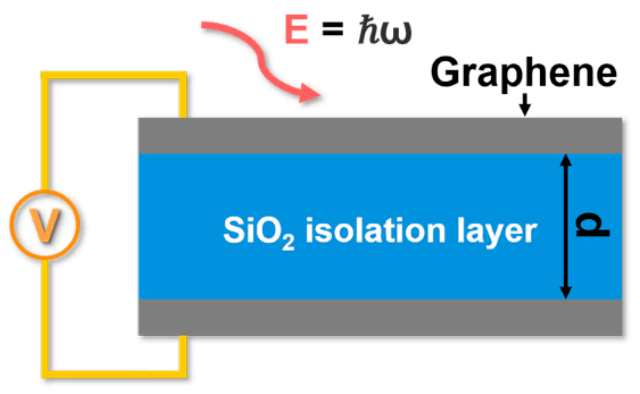

Figure 2. (a) Transmission spectrum of the dual built-in orthogonal slots waveguide (DBOSW) with and without graphene; (b) optical absorption in the graphene capacitor structure.

Two modes with different electric field polarizations are supported by the dual built-in orthogonal slots waveguide. The distributions of transversal and longitudinal electric field components of the transverse polarization (TM) mode and the complex-polarization mode (complex mode) are illustrated by $\left|E_{\mathrm{x}}\right|$ and $\left|E_{\mathrm{y}}\right|$, respectively. As depicted in Figure 3a, the TM mode is mainly distributed in the middle silica layer, which is attributed to the excitation of surface plasmon polarizations (SPPs) constrained by the top and bottom Ag layers. This $E_{\mathrm{y}}$-dominated plasmonic mode is similar to the optical mode constrained in the metal slot waveguide [21]. As shown in Figure 3b, the complex mode is mainly distributed in the upper slot and extends into the middle $\mathrm{SiO}_{2}$ layer. It should be noted that the complex mode can be seen as a mix of plasmonic modes supported by the crossed vertical metal slot and horizontal metal slot. In this case, both $E_{\mathrm{y}}$ and $E_{\mathrm{x}}$ components exist. The symmetry of both the horizontal and the vertical metal-insulator-metal (MIM) substructures lead to the spreading of transversal and longitudinal polarizations into the in-plane graphene-SiO $\mathrm{S}_{2}$-graphene layers, which is remarkably favorable to polarizationinsensitive modulation.
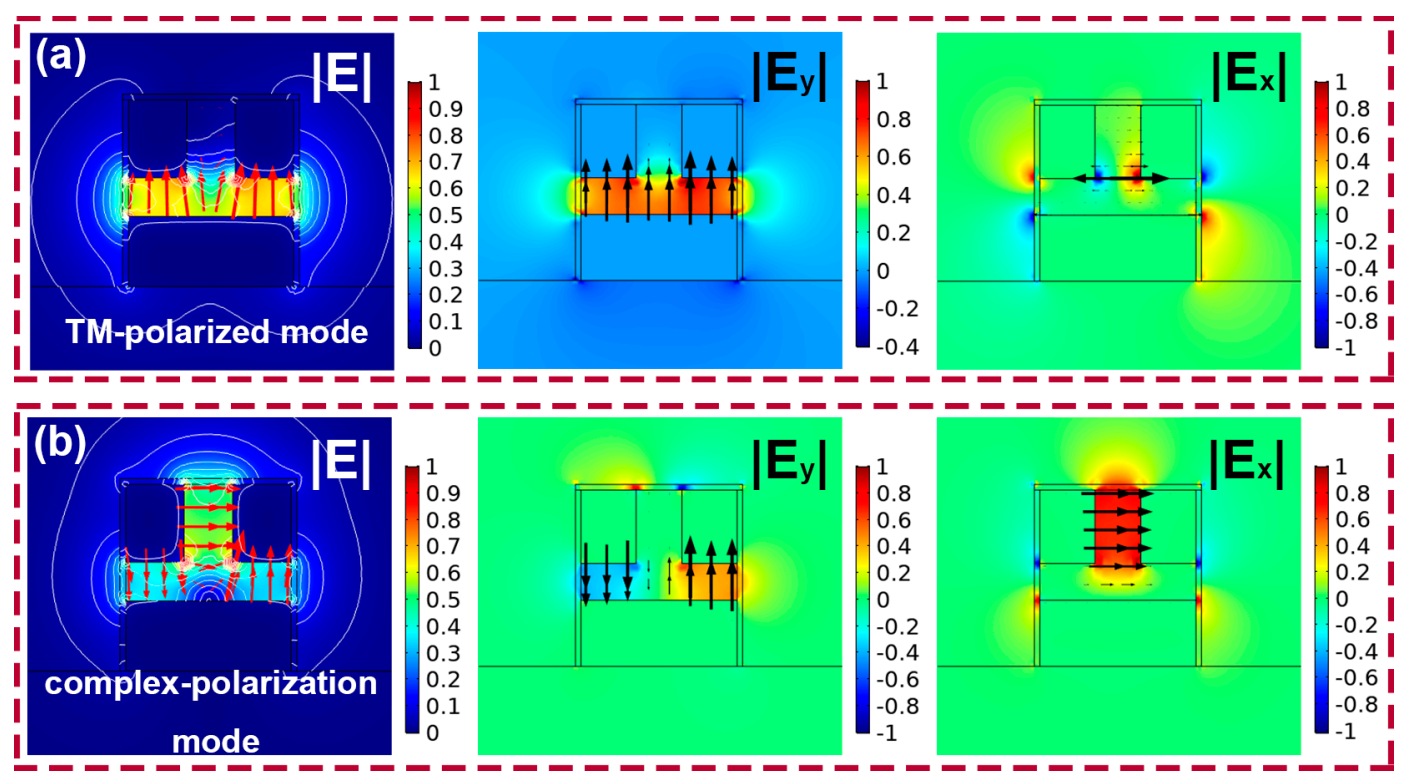

Figure 3. The electric field distributions of (a) transverse magnetic (TM) polarized mode and (b) complex-polarization mode. The color bars and arrows represent the intensity and direction of the electric field, respectively. 
In order to better illustrate the waveguide optimization and characterize the modulation performance of proposed design, the mode power attenuation (MPA), modulation depth (MD) and propagation loss (PL) are defined as follows:

$$
\begin{gathered}
\mathrm{MPA}=40 \pi\left(\log _{10} \mathrm{e}\right) \operatorname{Im}\left(N_{\mathrm{eff}}\right) / \lambda \\
\mathrm{MD}=\operatorname{MPA}(\mathrm{OFF})-\mathrm{MPA}(\mathrm{ON}) \\
\mathrm{PL}=\operatorname{MPA}(\mathrm{ON})
\end{gathered}
$$

where $\lambda$ is the incident wavelength, $\operatorname{Im}\left(N_{\text {eff }}\right)$ is the imaginary part of the effective index, MD is defined as the difference between MPA ("ON" state) and MPA ("OFF" state) and PL refers to MPA ("ON" state).

\subsection{Graphene Film}

Graphene is an emerging material with single layer carbon atoms in the form of hexagons. This unique structure offers graphene optical properties of controllable light absorption, considerable carrier mobility, uniform light absorption rate of $2.3 \%$ in a broadband, etc. [10,22-30]. These favorable properties imply the graphene has good potential in the application of high-speed, low-footprint and low-power consumption devices.

As shown in Figure 2b, a plate capacitor is formed by applying bias voltage to graphene layers. Light absorption is then controlled by the applied external electric field via the electrostatic doping effect. Since the interband transition in graphene is affected by Fermi level with no consideration of sign, both graphene layers can simultaneously be "transparent" at the high driving voltage, which refers to the "ON" state. An efficient numerical calculation method is important [31]. As has been reported [32], the graphene layer can be modeled as a 3D bulk material with a constant thickness or a 2D surface structure. To obtain accurate results, a smaller grid size is required in 3D simulations, which implies longer calculation time and larger memories requirement. On the basis of accuracy, it is desirable to model graphene as a 2D layer for higher efficiency. In this work, the graphene layer is considered a surface conductivity dielectric with a thickness of zero. Benefit from the reduced number of meshes, the calculation time reduces with accuracy guaranteed. The surface conductivity $\sigma_{\mathrm{g}}$ of the graphene may be adjusted by its chemical potential $\mu_{\mathrm{c}}$. This process can be well described by the Kubo formula [33], in which $\tau$ corresponds to the relaxation time, the intraband transition $\tau_{1}$ is $1.2 \mathrm{ps}$ and the interband transition $\tau_{2}$ is $15 \mathrm{fs}$. Graphene layers exhibit special physical properties at the epsilon-near-zero (ENZ) point, $\mu_{\mathrm{c}}(\mathrm{ENZ}) \approx 0.5 \mathrm{eV}$ [34]. When $\mu_{\mathrm{c}}$ is larger than $\mu_{\mathrm{c}}(\mathrm{ENZ})$, graphene shows the characteristics of the dielectric medium. Conversely, graphene behaves like a metallic layer and strong light absorption happens when $\mu_{\mathrm{c}}$ is smaller than $\mu_{\mathrm{c}}$ (ENZ). Equation (4) illustrates the relationship between chemical potential and bias voltage [30]:

$$
\mu_{\mathrm{c}}=\hbar v_{\mathrm{F}} \sqrt{\pi \eta\left|V_{\mathrm{g}}-V_{0}\right|}
$$

where $v_{\mathrm{F}}$ is the Fermi velocity of graphene $\left(v_{\mathrm{F}}=2.5 \times 10^{6} \mathrm{~m} / \mathrm{s}\right)$ [35]] and $\eta=\varepsilon_{\mathrm{r}} \varepsilon_{0} /$ de is derived from the parallel capacitor model $\left(\varepsilon_{\mathrm{r}}\right.$ and $d$ are the permittivity and thickness of $\mathrm{SiO}_{2}$ isolation layer, respectively). As shown in Figure $4, \mu_{\mathrm{c}}$ can shift from 0.2 to $0.6 \mathrm{eV}$ as the applied voltage changes from 0.608 to $5.442 \mathrm{~V}$. 


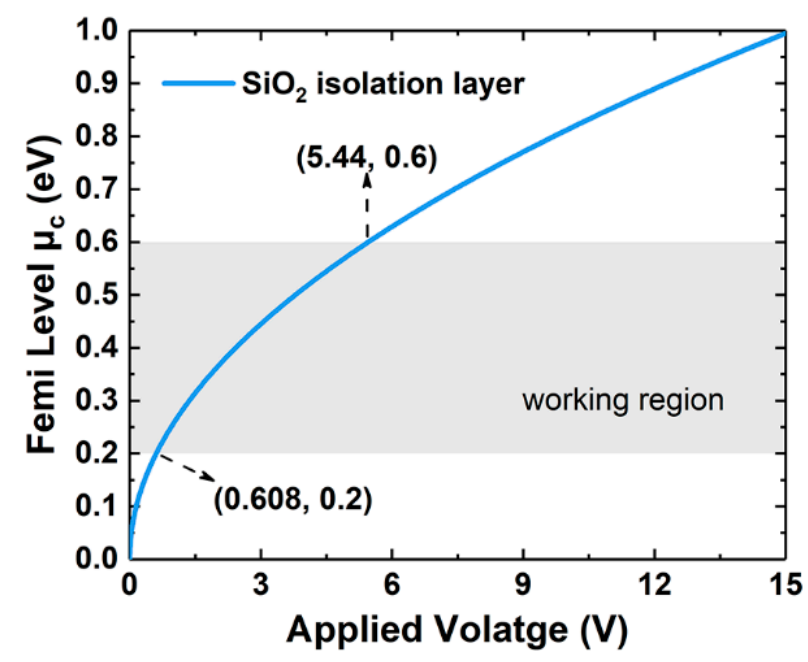

Figure 4. Fermi level $\mu_{\mathrm{c}}$ of graphene versus the change of applied external voltage.

\section{Design Optimization}

To confirm the effect of waveguide dimension on the mode field distribution, the impact of slot width change on the field confinement and metal absorption is investigated, as shown in the Figure $5 \mathrm{a}-\mathrm{d}(g=h=50)$ and Figure $5 \mathrm{e}-\mathrm{h}(g=h=200 \mathrm{~nm})$, respectively. When $g$ and $h$ increase, the field confinement profiles become slack, which handicap the light-graphene interaction. When a smaller slot width (e.g., $50 \mathrm{~nm}$ ) is adopted, a higher metal absorption can be expected, since the mode power extends more into the metal layers. When a relatively larger slot width (e.g., $200 \mathrm{~nm}$ ) is adopted, modes are mainly distributed in $\mathrm{SiO}_{2}$, which implies a relatively lower optical loss. Therefore, systematic dimension analysis is necessary to balance field confinement and metal absorption. In the following geometric discussions, MD is temporarily defined as the difference between MPA $\left(\mu_{\mathrm{c}}=1 \mathrm{eV}\right)$ and MPA $\left(\mu_{\mathrm{c}}=0 \mathrm{eV}\right)$, and PL refers to MPA $\left(\mu_{\mathrm{c}}=1 \mathrm{eV}\right)$ to stress the comparison. The effective index of DBOSW is also calculated at $\mu_{\mathrm{c}}=0$ and $1 \mathrm{eV}$. The polarization dependence of proposed design is studied by comparison of $N_{\text {eff }}$ at different $\mu_{\mathrm{c}}$ and geometric parameters.

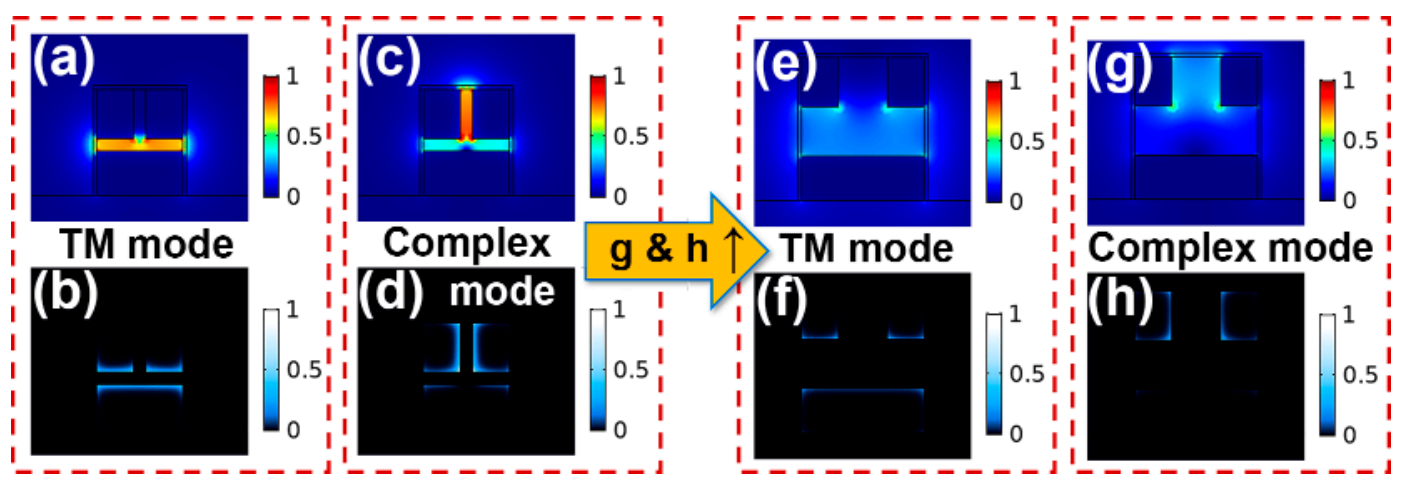

Figure 5. Comparison of normalized electric field distributions and ohmic loss profiles under different waveguide dimensions. When $h$ and $g$ are $50 \mathrm{~nm},(\mathbf{a}, \mathbf{b})$ are electric field distribution and ohmic loss profile for the TM mode, respectively; (c,d) are corresponding cases for the complex mode. When $h$ and $g$ are $200 \mathrm{~nm} ;(\mathbf{e}, \mathbf{f})$ are electric field distribution and ohmic loss profile for the TM mode, respectively; $(\mathbf{g}, \mathbf{h})$ are corresponding cases for the complex mode.

\section{1. $h_{b}$}

As mentioned above, the TM mode and complex mode in this hybrid waveguide can be regarded as compound polarizations supported by the vertical, as well as the horizontal $\mathrm{Ag}-\mathrm{SiO}_{2}-\mathrm{Ag}$ structure. The MD, PL and $\operatorname{Re}\left(N_{\text {eff }}\right)$ of the proposed modulator as a function of 
bottom Ag slab thickness $h_{\mathrm{b}}$ are shown in the Figure 6 . The analysis of $h_{\mathrm{b}}$ is implemented by a similar way adopted in the MIM waveguide model analysis, because it is also with thin metal layers [21]. Compared to complex mode, the TM mode is almost dominated by the longitudinal polarization, therefore the dimension change in vertical direction has a larger impact on the TM mode. Figure 6a shows that $\operatorname{Re}\left(N_{\text {eff }}\right)$ of the TM mode is more sensitive to $h_{\mathrm{b}}$ than that of complex mode. The $\operatorname{Re}\left(N_{\text {eff }}\right)$ of theTM mode keeps decreasing with the rising of $h_{\mathrm{b}}$, which decreases from 1.6993 to 1.6464 at $\mu_{\mathrm{c}}=1 \mathrm{eV}$ and 1.718 to 1.6654 at $\mu_{\mathrm{c}}=0 \mathrm{eV}$. Meanwhile, $\operatorname{Re}\left(N_{\mathrm{eff}}\right)$ of complex mode slowly decreases from $h_{\mathrm{b}}=50 \mathrm{~nm}$, and reaches to a stable value at $h_{\mathrm{b}}=150 \mathrm{~nm}$. In addition, as shown in Figure $6 \mathrm{c}$, the change in $h_{\mathrm{b}}$ has a significant impact on the PL of the TM mode that decreases with the increasing of $h_{\mathrm{b}}$ and reaches a stable value at $h_{\mathrm{b}}=150 \mathrm{~nm}$. In contrast, PL of complex mode remains at around $0.15 \mathrm{~dB} / \mu \mathrm{m}$ that is caused by the fraction of the TM mode distributed in the metal layer. This leads to a larger optical loss. The MD change of two modes versus $h_{\mathrm{b}}$ is very small, which is related to the limited influence of $h_{\mathrm{b}}$ on the light field distribution. The $\operatorname{Re}\left(\Delta N_{\text {eff }}\right)$ of two modes versus $h_{\mathrm{b}}$ is shown in Figure $6 \mathrm{~b}$. Here, $\operatorname{Re}\left(\Delta N_{\text {eff }}\right)$ is determined by

$$
\operatorname{Re}\left(\Delta N_{\text {eff }}\right)=\left|\operatorname{Re}\left(N_{\text {eff }}\right)_{\mathrm{TM} \text { mode }}-\operatorname{Re}\left(N_{\text {eff }}\right)_{\text {Complex mode }}\right|
$$

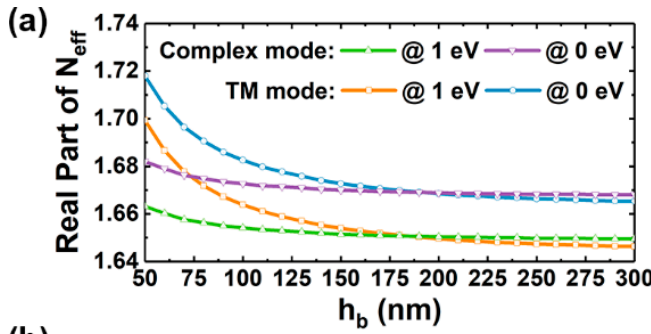

(b)
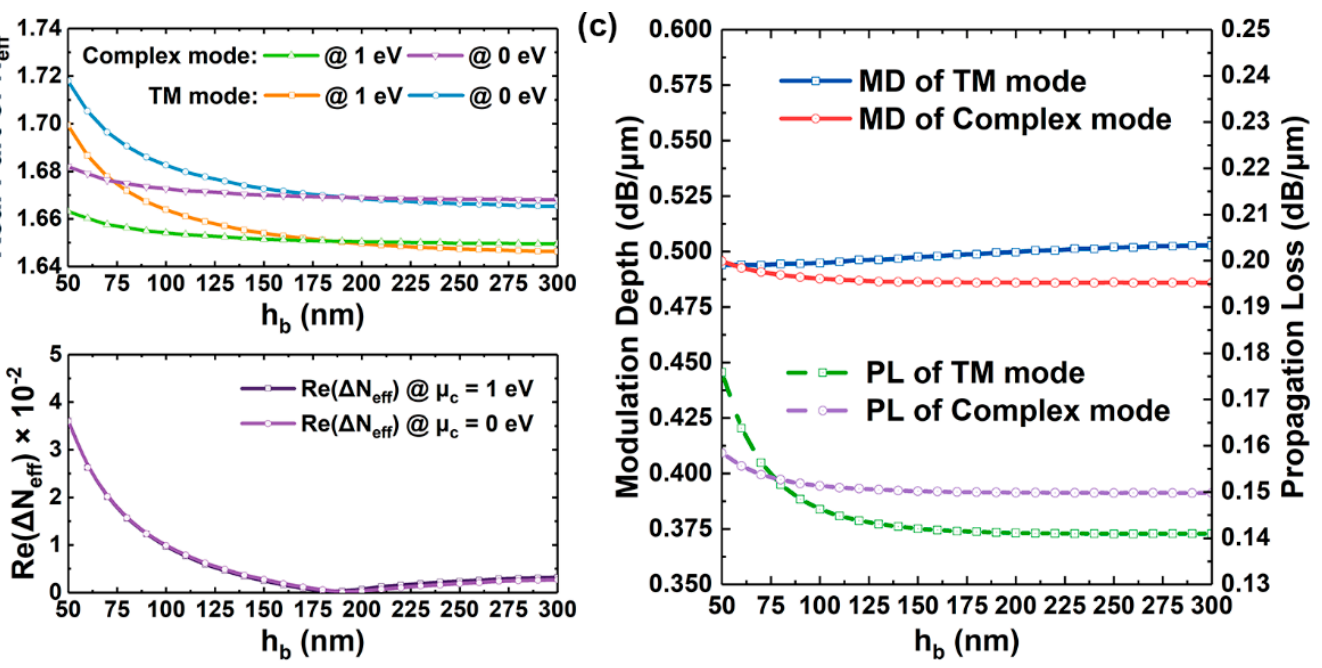

Figure 6. (a-c) are $\operatorname{Re}\left(N_{\text {eff }}\right), \operatorname{Re}\left(\Delta N_{\text {eff }}\right)$, and modulation depth (MD) as well as propagation loss (PL) of the TM mode and complex mode in the DBOSW modulator as a function of $h_{\mathrm{b}}$, respectively.

Since a low $\operatorname{Re}\left(\Delta N_{\text {eff }}\right)$ is more desirable, $h_{\mathrm{b}}$ is chosen to be $180 \mathrm{~nm}$.

\section{2. $h$}

Figure 7 shows the MD, PL, $\operatorname{Re}\left(N_{\text {eff }}\right)$ and $\operatorname{Re}\left(\Delta N_{\text {eff }}\right)$ of two modes in the DBOSW modulator versus the middle silica layer thickness $h$. As shown Figure $7 \mathrm{a}, \operatorname{Re}\left(N_{\text {eff }}\right)$ of both modes reduce consistently with the increasing of $h$. Furthermore, when $h=100 \mathrm{~nm}$, the $\operatorname{Re}\left(N_{\text {eff }}\right)$ of the TM mode and complex mode show a very close minimum, which can be confirmed in Figure $7 \mathrm{~b}$. Though $\operatorname{Re}\left(\Delta N_{\text {eff }}\right)$ can already be restrained at a low level $(<0.115)$ when $h$ is 50 or $200 \mathrm{~nm}$, the thickness of silica layer apparently has a more significant impact on the polarization dependence. As shown in Figure 7c, MD and PL of two modes decrease simultaneously with the increasing of $h$. These trends are attributed to less confinement of the light field in the middle silica layer as well as the weakening of the interaction with graphene. This is depicted in the illustration in Figure 7c. As $h$ decreases, the electric field intensity of the TM mode and the $y$-axis electric field component of complex mode increases in the middle silica layer. The increment of mode power in the metal layer invites higher optical loss. To be noted, the MD difference between the TM mode and complex 
mode remains at a low level when $h$ varies from 50 to $200 \mathrm{~nm}$. However, the PL of the TM mode becomes lower than that of complex mode when $h$ is higher than $95 \mathrm{~nm}$. To constrain the performance difference between the TM mode and complex mode, $h$ is chosen to be $100 \mathrm{~nm}$.

(a)

(b)
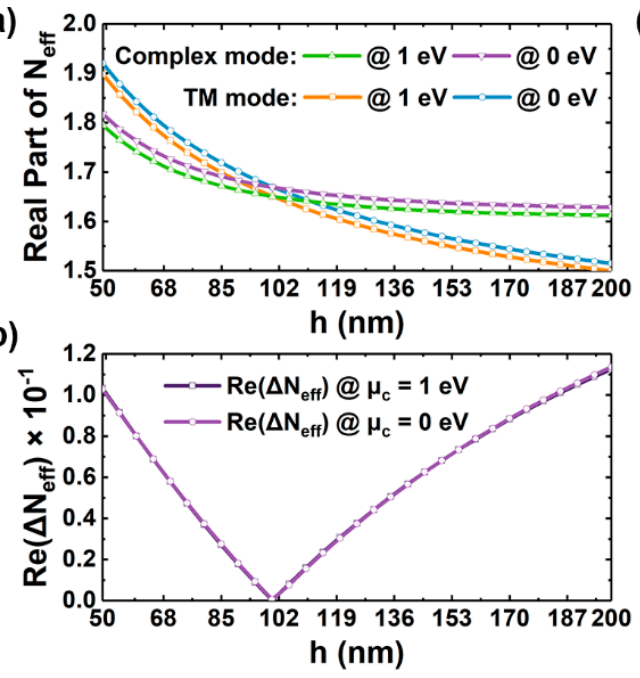

(c)

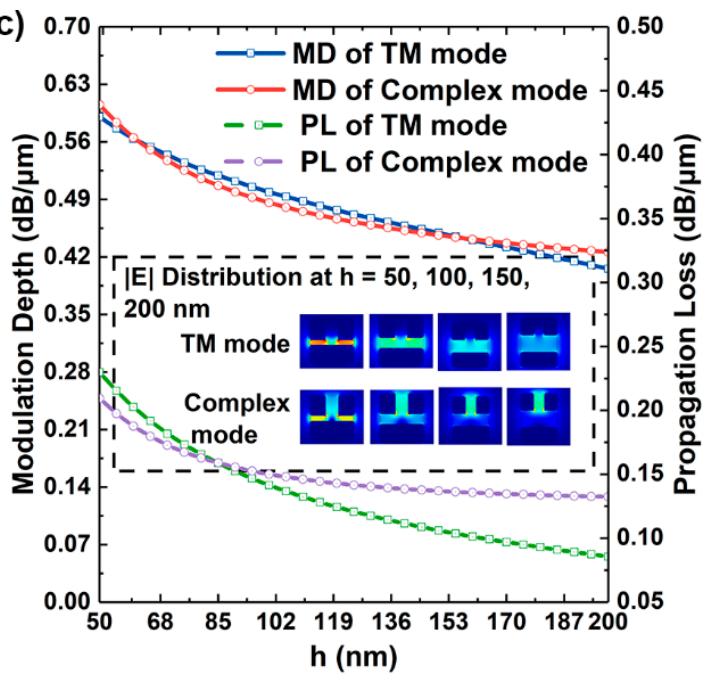

Figure 7. $\operatorname{Re}\left(N_{\text {eff }}\right), \operatorname{Re}\left(\Delta N_{\text {eff }}\right), \mathrm{MD}$ and PL of the TM mode and complex mode in the DBOSW modulator versus $h$ are shown in (a), (b) and (c), respectively. The illustration in (c) shows the variation of electric field distribution for both modes versus $h$.

\section{3. $h_{t}$}

When $h_{\mathrm{b}}=180 \mathrm{~nm}, h=100 \mathrm{~nm}, \operatorname{Re}\left(N_{\text {eff }}\right)$ and $\operatorname{Re}\left(\Delta N_{\text {eff }}\right)$, the MD and PL of two modes in the DBOSW modulator versus the top layer thickness $h_{\mathrm{t}}$ are investigated. As shown in Figure $8 \mathrm{a}, \operatorname{Re}\left(N_{\text {eff }}\right)$ of the TM mode decreases with the increment of $h_{\mathrm{t}}$ at $\mu_{\mathrm{c}}=0$ and $1 \mathrm{eV}$. When $h_{\mathrm{t}}$ is $110 \mathrm{~nm}, \operatorname{Re}\left(N_{\text {eff }}\right)$ of the complex mode exhibits a minimum of 1.6722 and 1.6469 at $\mu_{\mathrm{c}}=0$ and $1 \mathrm{eV}$, respectively. It is noteworthy that both modes share the same $\operatorname{Re}\left(N_{\text {eff }}\right)$ when $h_{\mathrm{t}}$ is $200 \mathrm{~nm}$ and $\mu_{\mathrm{c}}$ is $1 \mathrm{eV}$. This scenario also can be found when $h_{\mathrm{t}}$ is $210 \mathrm{~nm}$ and $\mu_{\mathrm{c}}$ is $0 \mathrm{eV}$. In Figure $8 \mathrm{~b}$, a maximum $\operatorname{Re}\left(\Delta N_{\text {eff }}\right)$ is first presented with the increase of $h_{\mathrm{t}}$ as $\mu_{\mathrm{c}}=0$ and $1 \mathrm{eV}$. Then, a minimum $\operatorname{Re}\left(\Delta N_{\mathrm{eff}}\right)$ of $6 \times 10^{-4}\left(\mu_{\mathrm{c}}=1 \mathrm{eV}\right)$ appears when $h_{\mathrm{t}}$ is $200 \mathrm{~nm}$. A minimum $\operatorname{Re}\left(\Delta N_{\text {eff }}\right)$ of $1 \times 10^{-4}\left(\mu_{\mathrm{c}}=0 \mathrm{eV}\right)$ can be observed when $h_{\mathrm{t}}$ is $210 \mathrm{~nm}$. The different behaviors of $\operatorname{Re}\left(N_{\text {eff }}\right)$ and $\operatorname{Re}\left(\Delta N_{\text {eff }}\right)$ in Figures $8 \mathrm{a}$ and $8 \mathrm{~b}$ can be explained by the change of fringing field distribution as well as the variation in the slot region. This phenomenon is similar to what happens to the MIM waveguide [20]. As shown in Figure 8c, the PLs of both the TM mode and the complex mode decrease till $h_{\mathrm{t}}$ rises up to $200 \mathrm{~nm}$. As $h_{\mathrm{t}}$ increases from $50 \mathrm{~nm}$ to $200 \mathrm{~nm}$, the MD of the complex mode decreases by $57.1 \%$, while the MD of the TM mode only reduces by $7.0 \%$. Obviously, the change of $h_{\mathrm{t}}$ has a more remarkable impact on the complex mode than that on the TM mode. This can be explained by the field distribution difference that can be observed from the illustration in Figure 8c. With comprehensive consideration, a balanced $h_{\mathrm{t}}$ of $200 \mathrm{~nm}$ is chosen.

\section{4. $w$}

For the waveguide structure in Figure 1, the width of the Ag strips $w$ will definitely affect the mode field distribution. Therefore, $\operatorname{Re}\left(N_{\text {eff }}\right), \operatorname{Re}\left(\Delta N_{\text {eff }}\right), \mathrm{MD}$ and PL of the TM mode and complex mode in the DBOSW modulator versus the Ag strips $w$ are investigated, when $h_{\mathrm{b}}=180 \mathrm{~nm}, h=100 \mathrm{~nm}$, and $h_{\mathrm{t}}=200 \mathrm{~nm}$. As shown in Figure $9 \mathrm{a}, \operatorname{Re}\left(N_{\text {eff }}\right)$ of the TM mode gradually increases from 1.631 to 1.675 at $\mu_{\mathrm{c}}=0 \mathrm{eV}$, when $w$ varies from 50 to $150 \mathrm{~nm}$. $\operatorname{Re}\left(N_{\text {eff }}\right)$ of the TM mode remains at 1.675 , without changing with the increment in $w$. Inversely, $\operatorname{Re}\left(N_{\text {eff }}\right)$ of complex mode decreases from 1.712 to 1.673 at $\mu_{\mathrm{c}}=0 \mathrm{eV}$, when $w$ 
varies from 50 to $150 \mathrm{~nm}$. A negligible change of $\operatorname{Re}\left(N_{\text {eff }}\right)$ of the complex mode is observed when $w$ is over $150 \mathrm{~nm}$. When $\mu_{\mathrm{c}}=1 \mathrm{eV}, \operatorname{Re}\left(N_{\text {eff }}\right)$ of the TM mode and complex mode exhibit similar inverse variation with the increment in $\mathrm{w}$, which leads to a turning point of $\operatorname{Re}\left(\Delta N_{\text {eff }}\right)$ at $w=150 \mathrm{~nm}$, as shown in Figure $9 \mathrm{~b}$.

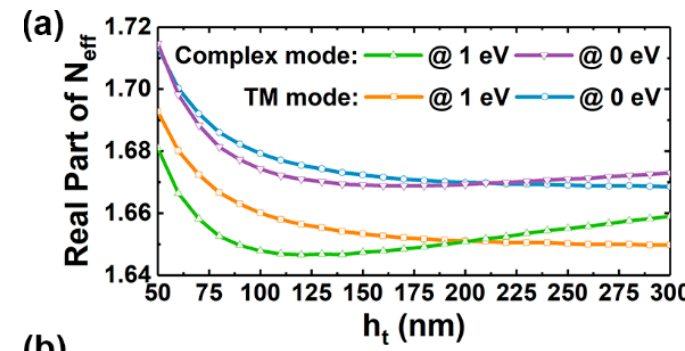

(b)
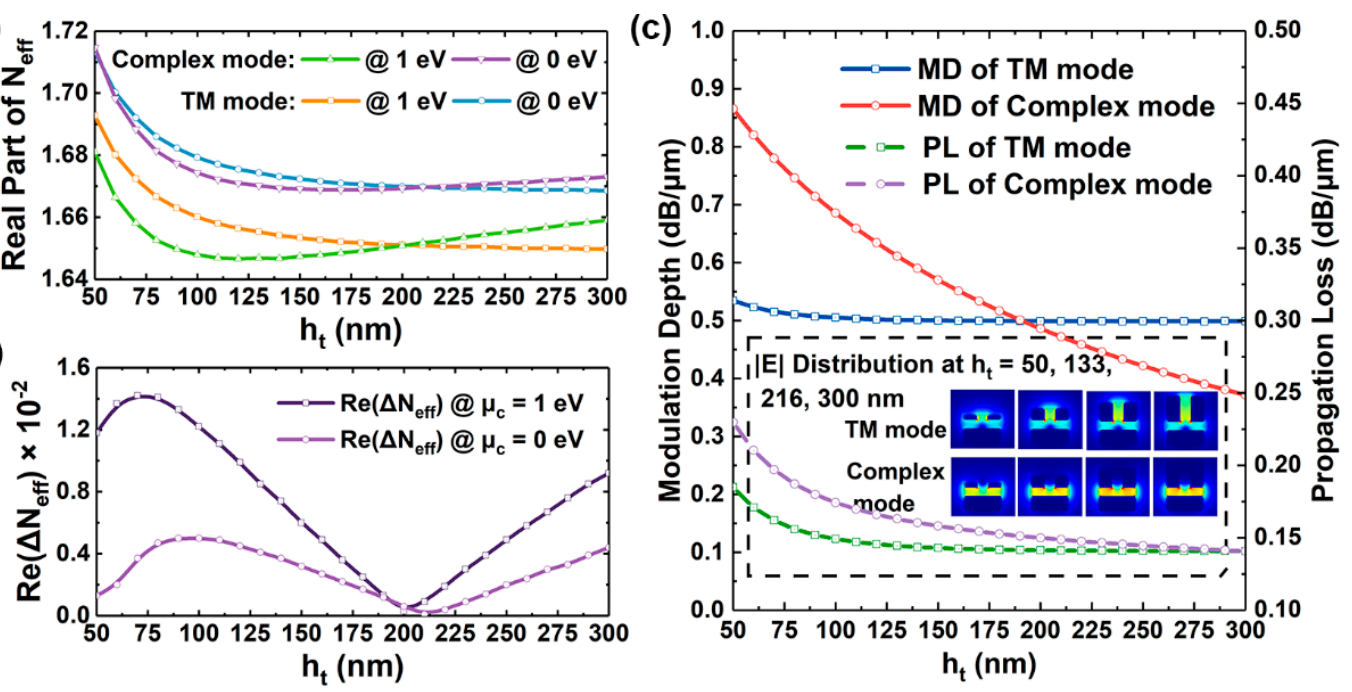

Figure 8. $\operatorname{Re}\left(N_{\text {eff }}\right), \operatorname{Re}\left(\Delta N_{\text {eff }}\right), \mathrm{MD}$ as well as PL of the TM mode and complex mode in the DBOSW modulator versus $h_{\mathrm{t}}$ are shown in (a), (b) and (c), respectively. The illustration in (c) shows the variation of electric field distribution for the TM mode and complex mode versus $h_{\mathrm{t}}$.
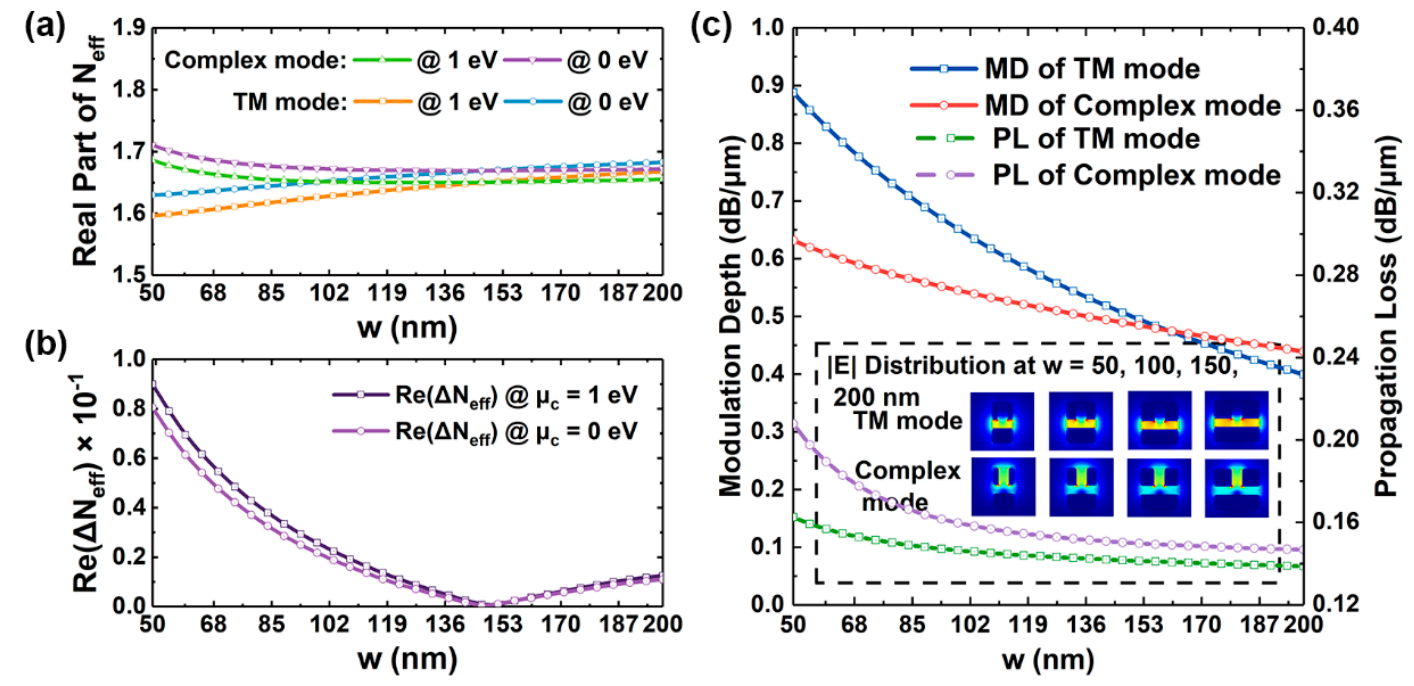

Figure 9. $\operatorname{Re}\left(N_{\text {eff }}\right), \operatorname{Re}\left(\Delta N_{\text {eff }}\right)$, modulation depth as well as propagation loss of the TM mode and complex mode in the DBOSW modulator versus $w$ are shown in $(\mathbf{a}),(\mathbf{b})$ and $(\mathbf{c})$, respectively. The illustration in (c) shows the variation of electric field distribution for both modes versus $w$.

As $w$ changes from $50 \mathrm{~nm}$ to $200 \mathrm{~nm}$, the MDs of the TM mode and complex mode decrease by 55.1 and $30.5 \%$, respectively. Both modes have the same MD at $w=160 \mathrm{~nm}$. When $w$ ranges from 50 to $150 \mathrm{~nm}$, the PL of the TM mode decreases from 0.16 to $0.14 \mathrm{~dB} / \mu \mathrm{m}$, while PL of complex mode from 0.21 to $0.15 \mathrm{~dB} / \mu \mathrm{m}$. Both PLs become stable when $w$ is larger than $150 \mathrm{~nm}$, as shown in Figure 9c. The decrement of the MD and PL can be attributed to the extension of the mode field region with the increment in $\mathrm{w}$, which weakens the graphene-light interaction strength, as shown in the illustration in Figure 9c. Since the TM mode and complex mode are distributed differently in the middle slot and the top 
metal slot, the increment in $w$ has a greater impact on the MD of the TM mode. Moreover, the enlargement of the mode field area will weaken the field intensity, and then the metal absorption, leading to a lower PL. From the above, $\operatorname{Re}\left(\Delta N_{\text {eff }}\right)$ shows a minimum, while the MDs and PLs of the two modes are very close at $w=150 \mathrm{~nm}$. Therefore, we choose $w$ to be $150 \mathrm{~nm}$ in following work.

\section{5. $g$}

Another parameter to be confirmed in the proposed design is the gap width $g$ between two upper metal parts. When $h_{\mathrm{b}}=180 \mathrm{~nm}, h=100 \mathrm{~nm}, w=150 \mathrm{~nm}$ and $h_{\mathrm{t}}=200 \mathrm{~nm}$, $\operatorname{Re}\left(N_{\text {eff }}\right), \operatorname{Re}\left(\Delta N_{\text {eff }}\right), \mathrm{MD}$ and PL of the two modes in the DBOSW modulator versus metal slot width $g$ are investigated. As shown in Figure 10, similar variations of $\operatorname{Re}\left(N_{\text {eff }}\right)$ and $\operatorname{Re}\left(\Delta N_{\text {eff }}\right)$ to that in Figure 9 can be observed.

(a)

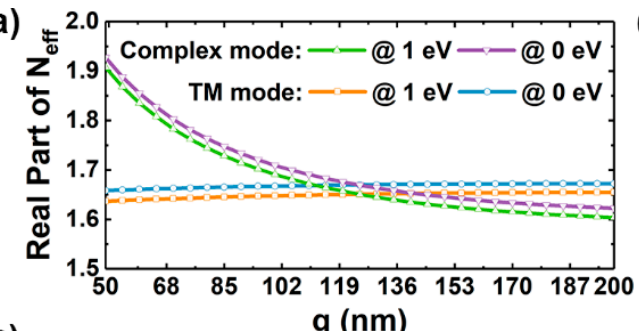

(b)

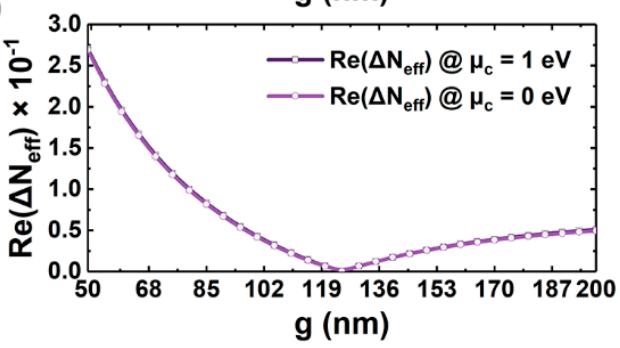

(c)

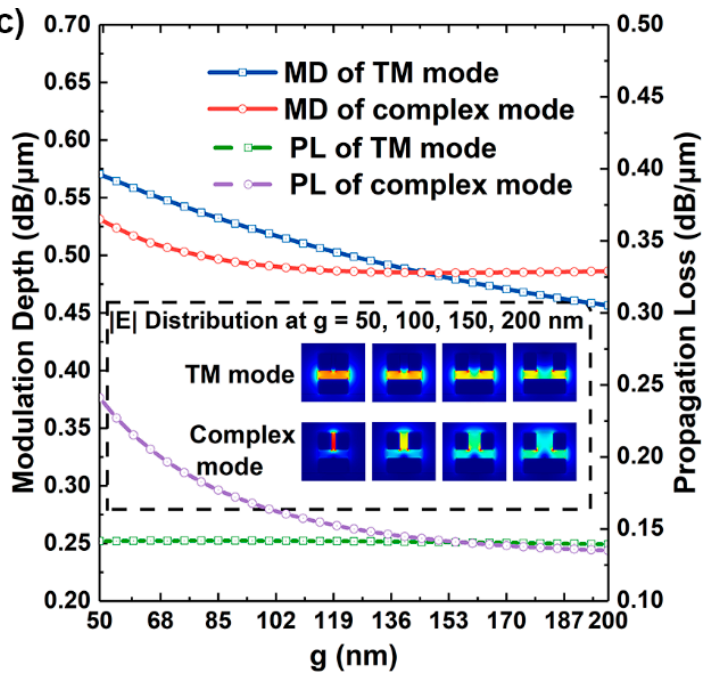

Figure 10. (a-c) are $\operatorname{Re}\left(N_{\text {eff }}\right), \operatorname{Re}\left(\Delta N_{\text {eff }}\right)$, modulation depth as well as propagation loss of the TM mode and complex mode in the DBOSW modulator versus $g$, respectively; the illustration in (c) shows the variation of electric field distribution for both modes versus $g$.

The difference is that the change of $g$ has a greater impact on $\operatorname{Re}\left(\Delta N_{\text {eff }}\right)$ than that on $\operatorname{Re}\left(N_{\text {eff }}\right)$. As $g$ increases, $\operatorname{Re}\left(\Delta N_{\text {eff }}\right)$ decreases firstly and then gradually increases. At $g=50 \mathrm{~nm}, \operatorname{Re}\left(\Delta N_{\text {eff }}\right)$ shows the maximum of 0.2707 and 0.2691 for $\mu_{\mathrm{c}}=0$ and $1 \mathrm{eV}$, respectively. The minimum $\operatorname{Re}\left(\Delta N_{\text {eff }}\right)$ of $6 \times 10^{-4}$ and $3 \times 10^{-4}$ can be found at $g=125 \mathrm{~nm}$ for $\mu_{\mathrm{c}}=0$ and $1 \mathrm{eV}$, respectively.

As shown in Figure 10c, the MD of the complex mode is less sensitive to the variation of $g$ than the TM mode, which is due to the enhanced interaction strength between the $x$-axis electric field component of complex mode caused by the smaller $g$ and the lateral metal slot. This leads to a higher loss and the resulting lower MD. In contrast, for the TM mode, the variation of $g$ only changes its mode area, which is similar to the impact of $w$ on the TM mode, as shown in the illustration in Figure 10c. The almost unchanged PL and linearly decreasing MD of the TM mode depicted in Figure 10c is consistent with the EA graphene modulator based on the MIM waveguide [36]. Since the difference of MD and PL between the two modes remains at a low level, when $g$ is larger than $125 \mathrm{~nm}, g$ is chosen to be $125 \mathrm{~nm}$ in this design.

\section{6. $\mu_{c}$ Response}

The relationships between $\operatorname{Re}\left(N_{\text {eff }}\right)\left(\operatorname{Re}\left(\Delta N_{\text {eff }}\right)\right), \operatorname{PL}, \operatorname{Im}\left(N_{\text {eff }}\right)$ and the chemical potential $\mu_{\mathrm{c}}$ also have been investigated. Figure 11a shows that $\operatorname{Re}\left(N_{\text {eff }}\right)$ of the TM mode first increases from 1.6699 to the peak value of 1.6772 as $\mu_{\mathrm{c}}$ increases from 0 to $0.4 \mathrm{eV}$. Subsequently, it decreases to 1.6511 as $\mu_{\mathrm{c}}$ continues to increase to $1 \mathrm{eV}$. Similar trends for 
$\operatorname{Re}\left(N_{\text {eff }}\right)$ of the complex mode can also be observed. Furthermore, the $\operatorname{Re}\left(\Delta N_{\text {eff }}\right)$ remains at a low level with an average of $3.6 \times 10^{-4}$ in the range of $\mu_{\mathrm{c}}=0$ to $1 \mathrm{eV}$. Figure $11 \mathrm{~b}$ shows that the PL decreases rapidly as $\mu_{\mathrm{c}}$ decreases from 0.2 to $0.6 \mathrm{eV}$. Therefore, the "ON" and the "OFF" state of DBOSW modulator is defined at $\mu_{\mathrm{c}}=0.6$ and $0.2 \mathrm{eV}$, respectively. In this case, the MD of the TM mode up to $0.474 \mathrm{~dB} / \mu \mathrm{m}$ can be obtained, while the MD of the complex mode is $0.462 \mathrm{~dB} / \mu \mathrm{m}$. The calculated $\Delta \mathrm{MD}\left(\left|\mathrm{MD}_{\mathrm{TM} \text { mode }}-\mathrm{MD}_{\text {Complex mode }}\right|\right)$ is only $0.012 \mathrm{~dB} / \mu \mathrm{m}$ at $\lambda=1550 \mathrm{~nm}$.
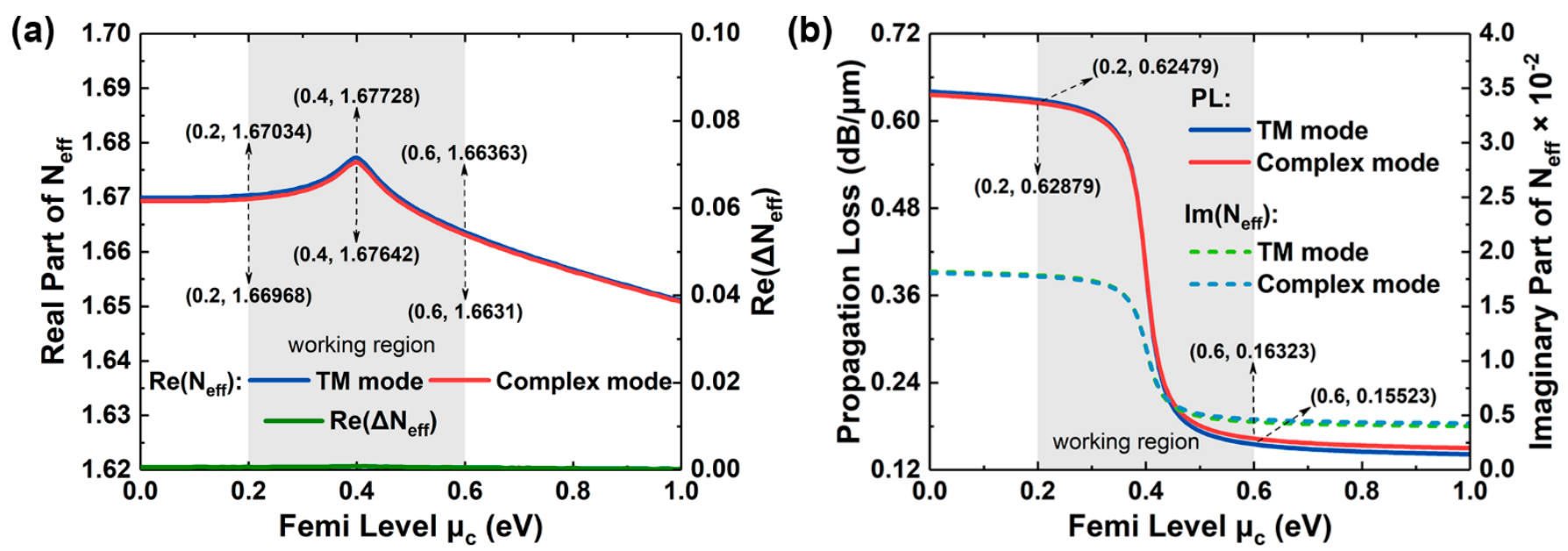

Figure 11. $\operatorname{Re}\left(N_{\text {eff }}\right)$ and $\operatorname{Re}\left(\Delta N_{\text {eff }}\right), \operatorname{Im}\left(N_{\text {eff }}\right)$ and PL of the TM mode and complex mode versus Femi level (chemical potential $\mu_{\mathrm{c}}$ ) from 0 to $1 \mathrm{eV}$ are shown in (a) and (b), respectively.

\section{Performance and Discussion}

\subsection{Optical Bandwidth}

To confirm the optical bandwidth of the DBOSW modulator with the above geometric parameters, the relationships between $\operatorname{Re}\left(N_{\text {eff }}\right)$ and $\operatorname{Re}\left(\Delta N_{\text {eff }}\right)$ of the two modes as a function of the incident wavelength are investigated when $\mu_{\mathrm{c}}$ ranges from 0.2 to $0.6 \mathrm{eV}$. As shown in Figure $12 \mathrm{a}, \operatorname{Re}\left(N_{\text {eff }}\right)$ decreases with the increment in wavelength. When $\lambda=1.1 \mu \mathrm{m}$ and $\mu_{\mathrm{c}}=0.6 \mathrm{eV}$, the maximum $\operatorname{Re}\left(N_{\mathrm{eff}}\right)$ of the TM mode and the complex mode is 1.7135 and 1.7163, respectively. When $\lambda=1.1 \mu \mathrm{m}$ and $\mu_{\mathrm{c}}=0.2 \mathrm{eV}, \operatorname{Re}\left(N_{\text {eff }}\right)$ of the TM mode and complex mode is 1.7096 and 1.7127, respectively. When $\lambda=1.9 \mu$ mand $\mu_{\mathrm{c}}=0.6 \mathrm{eV}, \operatorname{Re}\left(N_{\mathrm{eff}}\right)$ of the TM mode and complex mode is 1.6438 and 1.6427, respectively. When $\lambda=1.9 \mu \mathrm{m}$ and $\mu_{\mathrm{c}}=0.2 \mathrm{eV}, \operatorname{Re}\left(N_{\text {eff }}\right)$ of the TM mode and complex mode is 1.6586 and 1.6574 , respectively. It can be observed that a very low $\operatorname{Re}\left(\Delta N_{\text {eff }}\right)$ of around 0.001 can be obtained within a wavelength range from 1.1 to $1.9 \mu \mathrm{m}$.

In Figure $12 \mathrm{~b}$, when the wavelength varies from 1.1 to $1.9 \mu \mathrm{m}, \operatorname{Im}\left(N_{\text {eff }}\right)$ of the TM mode quickly increases from 0.01207 to 0.02164 at $\mu_{\mathrm{c}}=0.2 \mathrm{eV}$; meanwhile, $\operatorname{Im}\left(N_{\text {eff }}\right)$ of the complex mode increases from 0.01160 to 0.02177 at $\mu_{\mathrm{c}}=0.2 \mathrm{eV}$, which mainly results from the enhancement of the graphene-light interaction due to the increasing dielectric constant with the increment in optical wavelength. To be mentioned, the MPA change of both two modes is very limited within the wavelength range. The MDs of the TM mode are 0.40918 $\mathrm{dB} / \mu \mathrm{m}$ at $\lambda=1.1 \mu \mathrm{m}$ and $0.46931 \mathrm{~dB} / \mu \mathrm{m}$ at $\lambda=1.9 \mu \mathrm{m}$, respectively. While, the MDs of the complex mode are $0.38416 \mathrm{~dB} / \mu \mathrm{m}$ at $\lambda=1.1 \mu \mathrm{m}$ and $0.46415 \mathrm{~dB} / \mu \mathrm{m}$ at $\lambda=1.9 \mu \mathrm{m}$, respectively. Therefore, the proposed modulator shows good polarization-independence characteristics over a broad optical bandwidth. 

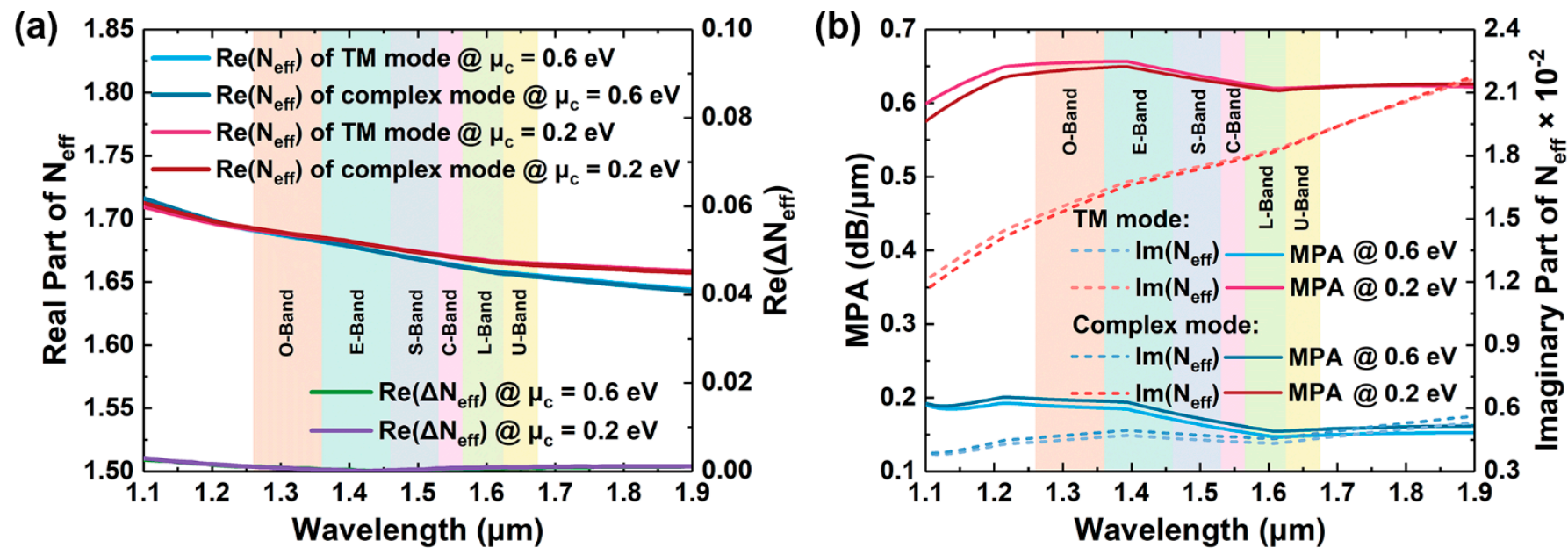

Figure 12. (a) $\operatorname{Re}\left(N_{\text {eff }}\right)$ and $\operatorname{Re}\left(\Delta N_{\text {eff }}\right)$, (b) $\operatorname{Im}\left(N_{\text {eff }}\right)$ and MPA of the TM mode and complex mode versus the incident wavelength at $\mu_{\mathrm{c}}=0.2$ and $0.6 \mathrm{eV}$, respectively.

\subsection{Frequency Response}

Here, the $3 \mathrm{~dB}$-bandwidth $\left(f_{3 \mathrm{~dB}}\right)$ and power consumption of the proposed DBOSW modulator with optimized geometric parameters are also confirmed. An equivalent circuit model is adopted to estimate the dynamic response of the DBOSW modulator, which is shown in Figure 13.

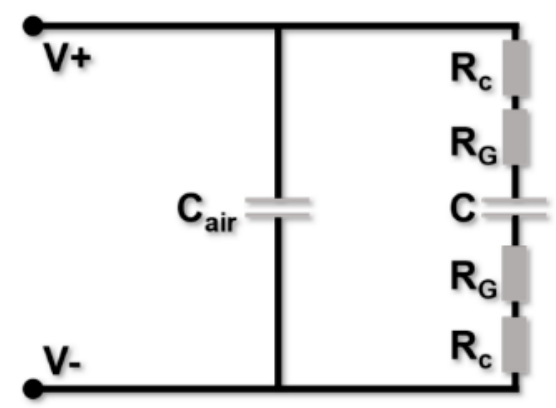

Figure 13. The equivalent circuit model.

In this model, the capacitance $C_{\text {air }}$ exists between two electrodes and the air, which is $12 \mathrm{fF}$ [37]. The capacitance $C$ that consists of the two graphene layers and $\mathrm{SiO}_{2}$ isolation layer includes both the dielectric capacitance $C_{\mathrm{D}}$ and the quantum capacitor $C_{\mathrm{Q}}$. Assuming the graphene layer is undoped $\left(n_{\mathrm{S}}=0\right)$, then we have $C_{\mathrm{Q}}=0$. Hence, the capacitance $C$ can be described by the following capacitor model:

$$
C=\varepsilon_{\mathrm{r}} \varepsilon_{0} w_{\mathrm{ol}} L / d
$$

where $L=20 \mu \mathrm{m}$ and $w_{\mathrm{ol}}=1385 \mathrm{~nm}$ are the graphene modulation length and the overlap width of two graphene layers, respectively. $\varepsilon_{\mathrm{r}}$ and $d$ are the permittivity and the thickness of $\mathrm{SiO}_{2}$ isolation layer, respectively. $R_{\text {total }}$ is the total resistance, which includes the graphene sheet resistance $R_{\mathrm{S}}$ of $100 \Omega / \square$ [38], and the metal electrode contact resistance to graphene layer $R_{\mathrm{c}}$ of $150 \Omega-\mu \mathrm{m}$ [20]. According to Equation (6) below, $R_{\text {total }}$ is calculated to be about $33.85 \Omega[24,30]$, where the effective graphene width $w_{\mathrm{g}}$ is set to be $1.885 \mu \mathrm{m}$.

$$
R_{\text {total }}=2 R_{\mathrm{s}} \times \frac{w_{\mathrm{g}}}{L}+\frac{2 R_{\mathrm{c}}}{L}
$$


Based on Equation (8), the $3 \mathrm{~dB}$-bandwidth is dominantly limited by $R C$ delay. According to Equations (5)-(7), the DBOSW modulator shows a high $f_{3 \mathrm{~dB}}$ of $101 \mathrm{GHz}$. For the proposed device structure, the silica as an isolation layer that is with a relatively low permittivity and a small thickness of $15 \mathrm{~nm}$ is favorable to compensate the disadvantages of the large effective width and overlapping area of graphene layers. In addition, the sheet resistance Rs and contact resistance $R_{\mathrm{c}}$ are values adopted in related Ref. [17].

$$
f_{3 \mathrm{~dB}}=\frac{1}{2 \pi R_{\text {total }} C_{\text {total }}}
$$

The power consumption $\left(E_{\mathrm{bit}}=C_{\text {total }}(\Delta \mathrm{U})^{2} / 4\right)$ is estimated to be $0.271 \mathrm{pJ} / \mathrm{bit}$ at $L=20 \mu \mathrm{m}$, where the applied voltage change $\Delta \mathrm{U}$ is $4.834 \mathrm{~V}$. This is in accordance with the change of chemical potential from 0.2 to $0.6 \mathrm{eV}$.

To clarify the merits of proposed design, the theoretical performance of the reported polarization-insensitive graphene modulators is comprehensively compared with that of this work. As shown in Table 1, the proposed modulator has the largest optical bandwidth and the smallest $\operatorname{Re}\left(\Delta N_{\text {eff }}\right)$. Moderate $\mathrm{MD}$ and $\Delta \mathrm{MD}$ also can be obtained. The characteristics of $f_{3 \mathrm{~dB}}$ and Ebit are also better than most reported works.

Table 1. Performance comparison with reported polarization-insensitive graphene modulators at $\lambda=1.55 \mu \mathrm{m}$.

\begin{tabular}{|c|c|c|c|c|c|c|}
\hline Ref. & Bandwidth (nm) & $\operatorname{Re}\left(\Delta N_{\text {eff }}\right)$ & $\mathrm{MD}(\mathrm{dB} / \mu \mathrm{m})$ & $\Delta \mathrm{MD}(\mathrm{dB} / \mu \mathrm{m})$ & $f_{3 \mathrm{~dB}}(\mathrm{GHz})$ & $E_{\text {bit }}(\mathrm{fJ} / \mathrm{bit})$ \\
\hline [39] & $1500-1600$ & - & 0.06 & 0 & 13.4 & - \\
\hline [40] & $1500-1600$ & - & 0.08 & 0 & 80 & - \\
\hline [41] & $1200-1600$ & - & $\begin{array}{l}\text { mode A: } 1.05 \\
\text { mode B: } 1.13 \\
\text { mode } C: 0.52\end{array}$ & $\begin{array}{l}\text { Min: } 0.08 \\
\text { Max: } 0.61\end{array}$ & 95 & 138.8 \\
\hline [42] & $1530-1565$ & $4.7 \times 10^{-3}$ & $\begin{array}{l}\text { TM mode: } \sim 0.2975 \\
\text { TE mode: } \sim 0.2895\end{array}$ & $\sim 8 \times 10^{-3}$ & 30.2 & 2980 \\
\hline [43] & 1367-1771 & $\sim 0.5$ & $\begin{array}{l}\text { TM mode: } 1.113 \text {, } \\
\text { TE mode: } 1.119\end{array}$ & $\sim 6 \times 10^{-3}$ & 6.1 & 7800 \\
\hline [44] & $1450-1650$ & $\sim 0.1$ & $\begin{array}{l}\text { TM mode: } 1.392, \\
\text { TE mode: } 1.347\end{array}$ & 0.045 & $\sim 100$ & - \\
\hline$[45]$ & $1300-1800$ & $1.2 \times 10^{-3}$ & - & - & 135.6 & - \\
\hline This work & 1100-1900 & $6 \times 10^{-4}$ & $\begin{array}{c}\text { TM mode: } 0.474, \\
\text { complex mode: } 0.462\end{array}$ & 0.012 & 101 & 271 \\
\hline
\end{tabular}

The proposed DBOSW modulator can be implemented through the following fabrication process. The fabrication process starts with a commercial silica wafer. The E-beam evaporation deposits a silver layer with a thickness of $180 \mathrm{~nm}\left(h_{\mathrm{b}}\right)$ onto the silica surface, serving as a bottom layer. Subsequently, the plasma-enhanced chemical vapor deposition (PECVD) can be used to deposit the $100 \mathrm{~nm}$-thick $\mathrm{SiO}_{2}(h)$ middle layer. Next, the thermal evaporation is used to deposit a $200 \mathrm{~nm}$-thick $\left(h_{\mathrm{t}}\right)$ silver layer followed by electron-beam lithography (EBL) and inductively coupled plasma etching. The $125 \mathrm{~nm}$-wide metal slot substructure $(g)$ is then filled with $\mathrm{SiO}_{2}$ by PECVD. The subsequent surface chemical mechanical polishing as well as the etching to three layers above can form a hybrid ridge with a width of $425 \mathrm{~nm}(w \times 2+g)$. After that, the bottom graphene sheet grown can be wet-transferred to the hybrid ridge waveguide. The graphene-covered region can be defined by EBL processing to remove the excess graphene. Whereas, the graphene on the other side extends $500 \mathrm{~nm}$ to form an electrode contact. A $15 \mathrm{~nm}$-thick $\mathrm{SiO}_{2}$ isolation layer is deposited on the bottom graphene flake. The second graphene flake is transferred onto the $\mathrm{SiO}_{2}$ isolation layer and handled with the same process applied on the bottom graphene layer, constructing a complete hybrid waveguide structure. 
Considering the structural complexity of the proposed DBOSW, the influence of manufacturing errors on the modulator is also evaluated. Firstly, the influence of inequality of the top $\mathrm{Ag}$ strip $\delta$ (the asymmetry of DBOSW) on the modulator performance is investigated, as shown in Figure 14. The geometric parameters used here are the optimal values discussed in above sections. It can be seen that the DBOSW modulator exhibits stable polarization insensitivity in the fluctuation of one side $\mathrm{w}$ from 135 to $165 \mathrm{~nm}(-15 \mathrm{~nm}>\delta>15 \mathrm{~nm})$. The maximum $\operatorname{Re}\left(\Delta N_{\text {eff }}\right)$ at $\delta=15 \mathrm{~nm}$ is $4 \times 10^{-3}$, which is still lower than the optimal value in Ref. [40]. $\Delta \mathrm{MD}$ remains at a low level, which is still competitive compared with reported works. The undulation of $\triangle \mathrm{MD}$ relates to the difference between the mutative MD of the TM mode and the relatively constant MD of the complex mode, as shown in Figure 14c. PLs exhibit good stability. As discussed in Section 3, though the proposed design has a relatively large fabrication tolerance, $g$ needs to be treated carefully. A significant negative effect on $\operatorname{Re}\left(N_{\text {eff }}\right)$ may damage the modulation performance at small $g$.

(a)

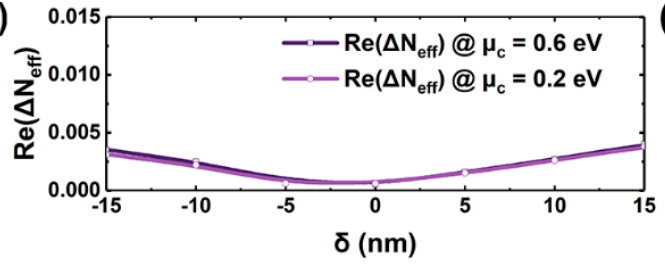

(b)

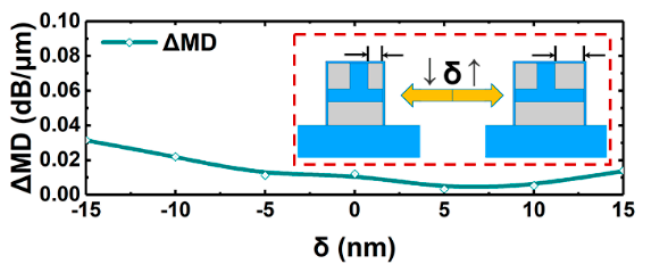

(c)

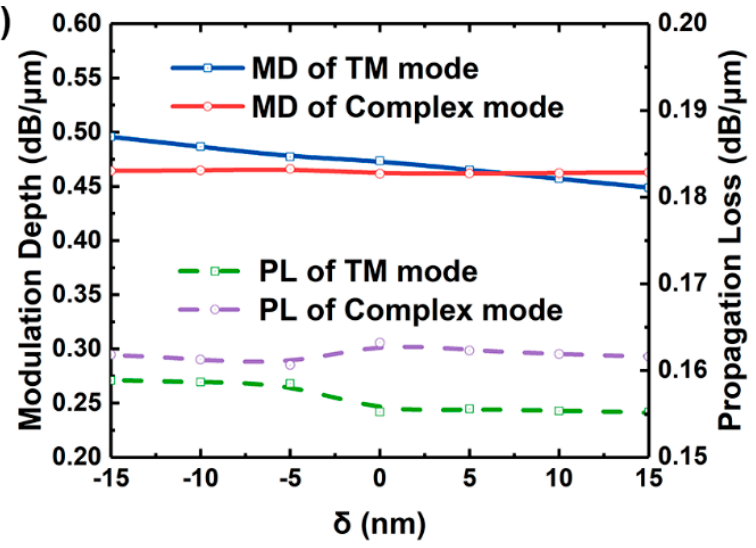

Figure 14. The inequality of the top $\operatorname{Ag}$ strip $\delta$ on (a) $\operatorname{Re}\left(\Delta N_{\text {eff }}\right) ;(\mathbf{b}) \Delta \mathrm{MD}$; and (c) MD, PL of the TM mode and complex mode. The illustration in (b) shows the unequal condition of the DBOSW modulator, when $\delta<0$ the width of the right $\mathrm{Ag}$ stripe is smaller than that of the left one.

\section{Conclusions}

In summary, to achieve the polarization-insensitive modulation and enhance the modulation capability of the graphene layer, a broadband polarization-insensitive graphene modulator based on plasmonic effect with DBOSW is proposed and comprehensively investigated. By introducing the two slot-like structure in the waveguide, the DBOSW can support two modes simultaneously, which enables the modulation of both the longitudinal and the transverse polarization electric fields in a broadband bandwidth. When the external bias voltage shifts from 0.608 to $5.442 \mathrm{~V}$, the MD of 0.474 and $0.462 \mathrm{~dB} / \mu \mathrm{m}$ for the TM mode and complex mode can be obtained, respectively. A low effective index difference with an average of 0.001 is achieved within a wide optical band range from 1.1 to $1.9 \mu \mathrm{m}$. The 3 $\mathrm{dB}$-bandwidth of $101 \mathrm{GHz}$ and a power consumption of $0.271 \mathrm{pJ} /$ bit at a modulation length of $20 \mu \mathrm{m}$ can be obtained. The proposed graphene modulator has potential in microwave photonic systems.

Author Contributions: W.C. proposed the idea, carried out the simulations and wrote the manuscript. Y.X. and Y.G. plotted the figures and provided suggestions. X.W. supervised the simulations. X.S. and D.Z. supervised the whole work, interpreted the results and improved the manuscript. All authors reviewed the manuscript. All authors have read and agreed to the published version of the manuscript.

Funding: This study was supported by the National Key Research and Development Program of China (2019YFB2203001), National Natural Science Foundation of China $(61675087,61875069)$, and The Education Department of Jilin Province (JJKH20190118KJ). 
Institutional Review Board Statement: Not applicable.

Informed Consent Statement: Not applicable.

Conflicts of Interest: The authors declare no conflict of interest.

\section{References}

1. Marris-Morini, D.; Lyan, P.; Rivallin, P.; Halbwax, M.; Laval, S.; Vivien, L.; Rasigade, G.; Fedeli, J.-M.; Cassan, E.; Le Roux, X.; et al. Recent Progress in High-Speed Silicon-Based Optical Modulators. Proc. IEEE 2009, 97, 1199-1215. [CrossRef]

2. Wang, C.; Zhang, M.; Chen, X.; Bertrand, M.; Shams-Ansari, A.; Chandrasekhar, S.; Winzer, P.; Lončar, M. Integrated lithium niobate electro-optic modulators operating at CMOS-compatible voltages. Nature 2018, 562, 101-104. [CrossRef] [PubMed]

3. Pérez-Galacho, D.; Marris-Morini, D.; Stoffer, R.; Cassan, E.; Vivien, L. Simplified modeling and optimization of silicon modulators based on free-carrier plasma dispersion effect. Opt. Express 2016, 24, 26332-26337. [CrossRef]

4. Park, J.-K.; Takagi, S.; Takenaka, M. InGaAsP Mach-Zehnder interferometer optical modulator monolithically integrated with InGaAs driver MOSFET on a III-V CMOS photonics platform. Opt. Express 2018, 26, 4842-4852. [CrossRef]

5. Nickelson, L.; Gric, T.; Asmontas, S.; Martavicius, R. Electric Field Distributions of the Fast and Slow Modes Propagated in the Open Rod SiC Waveguide. Elektron. Elektrotech. 2009, 93, 87-90.

6. Hu, Y.; Pantouvaki, M.; Van Campenhout, J.; Brems, S.; Asselberghs, I.; Huyghebaert, C.; Absil, P.; Van Thourhout, D. Broadband $10 \mathrm{~Gb} / \mathrm{s}$ operation of graphene electro-absorption modulator on silicon. Laser Photon. Rev. 2016, 10, 307-316. [CrossRef]

7. Mohsin, M.; Schall, D.; Otto, M.; Noculak, A.; Neumaier, D.; Kurz, H. Graphene based low insertion loss electro-absorption modulator on SOI waveguide. Opt. Express 2014, 22, 15292-15297. [CrossRef]

8. Dalir, H.; Xia, Y.; Wang, Y.; Zhang, X. Athermal Broadband Graphene Optical Modulator with 35 GHz Speed. ACS Photonics 2016, 3, 1564-1568. [CrossRef]

9. Phatak, A.; Cheng, Z.Z.; Qin, C.Y.; Goda, K. Design of electro-optic modulators based on graphene-on-silicon slot waveguides. Opt. Lett. 2016, 41, 2501-2504. [CrossRef] [PubMed]

10. Liu, M.; Yin, X.; Ulin-Avila, E.; Geng, B.; Zentgraf, T.; Ju, L.; Wang, F.; Zhang, X. A graphene-based broadband optical modulator. Nature 2011, 474, 64-67. [CrossRef]

11. Liu, M.; Yin, X.; Zhang, X. Double-Layer Graphene Optical Modulator. Nano Lett. 2012, 12, 1482-1485. [CrossRef]

12. Phare, C.T.; Daniel Lee, Y.-H.; Cardenas, J.; Lipson, M. Graphene electro-optic modulator with 30 GHz bandwidth. Nat. Photonics 2015, 9, 511-514. [CrossRef]

13. Schuller, J.A.; Barnard, E.S.; Cai, W.; Jun, Y.C.; White, J.S.; Brongersma, M.L. Plasmonics for extreme light concentration and manipulation. Nat. Mater. 2010, 9, 193-204. [CrossRef]

14. Bozhevolnyi, S.I.; Volkov, V.S.; Devaux, E.; Laluet, J.Y.; Ebbesen, T.W. Channel plasmon subwavelength waveguide components including interferometers and ring resonators. Nature 2006, 440, 508-511. [CrossRef] [PubMed]

15. Gramotnev, D.K.; Bozhevolnyi, S.I. Plasmonics beyond the diffraction limit. Nat. Photonics 2010, 4, 83-91. [CrossRef]

16. Huang, B.-H.; Lu, W.-B.; Li, X.-B.; Wang, J.; Liu, Z.-G. Waveguide-coupled hybrid plasmonic modulator based on graphene. Appl. Optics 2016, 55, 5598-5602. [CrossRef] [PubMed]

17. Zheng, P.; Yang, H.; Fan, M.; Hu, G.; Zhang, R.; Yun, B.; Cui, Y. A Hybrid Plasmonic Modulator Based on Graphene on Channel Plasmonic Polariton Waveguide. Plasmonics 2018, 13, 2029-2035. [CrossRef]

18. Bao, Q.; Zhang, H.; Wang, B.; Ni, Z.; Lim, C.H.Y.X.; Wang, Y.; Tang, D.Y.; Loh, K.P. Broadband graphene polarizer. Nat. Photonics 2011, 5, 411-415. [CrossRef]

19. Chang, L.-M.; Liu, L.; Gong, Y.-H.; Tan, M.-Q.; Yu, Y.-D.; Li, Z.-Y. Polarization-independent directional coupler and polarization beam splitter based on asymmetric cross-slot waveguides. Appl. Optics 2018, 57, 678-683. [CrossRef]

20. Zhong, H.; Zhang, Z.Y.; Chen, B.Y.; Xu, H.T.; Yu, D.M.; Huang, L.; Peng, L.M. Realization of low contact resistance close to theoretical limit in graphene transistors. Nano Res. 2015, 8, 1669-1679. [CrossRef]

21. Veronis, G.; Fan, S. Modes of Subwavelength Plasmonic Slot Waveguides. J. Lightwave Technol. 2007, 25, 2511-2521. [CrossRef]

22. Geim, A.K.; Novoselov, K.S. The rise of graphene. Nat. Mater. 2009, 6, 183-191. [CrossRef]

23. Schwierz, F. Graphene transistors. Nat. Nanotechnol. 2010, 5, 487-496. [CrossRef] [PubMed]

24. Bonaccorso, F.; Hasan, T.; Sun, Z.; Ferrari, A.C. Graphene photonics and optoelectronics. Nat. Photonics 2010, 4, 611-622. [CrossRef]

25. Kusuma, J.; Balakrishna, R.G.; Patil, S.; Jyothi, M.S.; Chandan, H.R.; Shwetharani, R. Exploration of graphene oxide nanoribbons as excellent electron conducting network for third generation solar cells. Solar Energy Mater. Solar Cells 2018, 183, $211-219$. [CrossRef]

26. Avouris, P.; Chen, Z.; Perebeinos, V. Carbon Based Electronics. Nat. Nanotechnol. 2007, 2, 605-615. [CrossRef] [PubMed]

27. Bolotin, K.I.; Sikes, K.J.; Jiang, Z.; Klima, M.; Fudenberg, G.; Hone, J.; Kim, P.; Stormer, H.L. Ultrahigh electron mobility in suspended graphene. Solid State Commun. 2008, 146, 351-355. [CrossRef]

28. Nair, R.R.; Blake, P.; Grigorenko, A.N.; Novoselov, K.S.; Booth, T.J.; Stauber, T.; Peres, N.M.R.; Geim, A.K. Fine Structure Constant Defines Visual Transparency of Graphene. Science 2008, 320, 1308. [CrossRef] [PubMed]

29. Mak, K.F.; Sfeir, M.Y.; Wu, Y.; Lui, C.H.; Misewich, J.A.; Heinz, T.F. Measurement of the Optical Conductivity of Graphene. Phys. Rev. Lett. 2008, 101, 196405-196408. [CrossRef] [PubMed] 
30. Sensale-Rodriguez, B.; Yan, R.; Kelly, M.M.; Fang, T.; Tahy, K.; Hwang, W.S.; Jena, D.; Liu, L.; Xing, H.G. Broadband graphene terahertz modulators enabled by intraband transitions. Nat. Commun. 2012, 3, 780-786. [CrossRef]

31. Gric, T.; Nickelson, L.; Asmontas, S. Electrodynamical characteristic particularity of open metamaterial square and circular waveguides. Prog. Electromagn. Res. 2010, 109, 361-379. [CrossRef]

32. Ye, L.; Sui, K.; Zhang, Y.; Liu, Q.H. Broadband optical waveguide modulators based on strongly coupled hybrid graphene and metal nanoribbons for near-infrared applications. Nanoscale 2019, 11, 3229-3239. [CrossRef] [PubMed]

33. Hanson, G.W. Dyadic Green's functions and guided surface waves for a surface conductivity model of graphene. J. Appl. Phys. 2007, 103, 064302-064309. [CrossRef]

34. Kwon, M.-S. Discussion of the Epsilon-Near-Zero Effect of Graphene in a Horizontal Slot Waveguide. IEEE Photonics J. 2014, 6 , 1-9. [CrossRef]

35. Hwang, C.; Siegel, D.A.; Mo, S.K.; Regan, W.; Ismach, A.; Zhang, Y.; Zettl, A.; Lanzara, A. Fermi velocity engineering in graphene by substrate modification. Sci. Rep. 2012, 2, 590-593. [CrossRef]

36. Ding, Y.; Guan, X.; Zhu, X.; Hao, H.; Xiao, S. Effective electro-optic modulation in low-loss graphene-plasmonic slot waveguides. Nanoscale 2017, 9, 15576-15581. [CrossRef]

37. Hu, Y.; Xiao, X.; Xu, H.; Li, X.; Xiong, K.; Li, Z.; Chu, T.; Yu, Y.; Yu, J. High-speed silicon modulator based on cascaded microring resonators. Opt. Express 2012, 20, 15079-15085. [CrossRef]

38. Abdollahi Shiramin, L.; Van Thourhout, D. Graphene Modulators and Switches Integrated on Silicon and Silicon Nitride Waveguide. IEEE J. Sel. Top. Quantum Electron. 2016, 23, 94-100. [CrossRef]

39. Yang, Z.; Lu, R.; Cai, S.; Wang, Y.; Zhang, Y.; Wang, X.; Liu, Y. A CMOS-compatible and polarization-insensitive graphene optical modulator. Opt. Commun. 2019, 450, 130-135. [CrossRef]

40. Yang, Z.; Lu, R.; Wang, Y.; Cai, S.; Zhang, Y.; Wang, X.; Liu, Y. A fabrication-friendly graphene-based polarization insensitive optical modulator. Optik 2019, 182, 1093-1098. [CrossRef]

41. Shirdel, M.; Mansouri-Birjandi, M.A. Broadband graphene modulator based on a plus-shaped plasmonic slot waveguide. Appl. Optics 2019, 58, 8174-8179. [CrossRef]

42. Hu, X.; Wang, J. Design of graphene-based polarization-insensitive optical modulator. Nanophotonics 2018, 7, 651-658. [CrossRef]

43. Xu, Y.; Li, F.; Kang, Z.; Huang, D.; Zhang, X.; Tam, H.-Y.; Wai, P. Hybrid Graphene-Silicon Based Polarization-Insensitive Electro-Absorption Modulator with High-Modulation Efficiency and Ultra-Broad Bandwidth. Nanomaterials 2019, 9, 157-171. [CrossRef] [PubMed]

44. Ye, S.W.; Liang, D.; Lu, R.-G.; Shah, M.K.; Zou, X.-H.; Yang, F.; Yuan, F.; Liu, Y. Polarization Independent Modulator by Partly Tilted Graphene Induced Electro-Absorption Effect. IEEE Photonics Technol. Lett. 2016, 29, 23-26. [CrossRef]

45. Zou, X.H.; Zhang, Y.J.; Li, Z.H.; Yang, Y.W.; Zhang, S.J.; Zhang, Z.Y.; Zhang, Y.L.; Liu, Y. Polarization-Insensitive Phase Modulators Based on an Embedded Silicon-Graphene-Silicon Waveguide. Appl. Sci.-Basel 2019, 9, 429-436. [CrossRef] 